\title{
Proteína tau e as doenças neurodegenerativas
}

\author{
Dr. Fabiano de Abreu Agrela Rodrigues \\ deabreu.fabiano@gmail.com \\ Biólogo, Neurocientista, Doutor em Ciências da Saúde \\ nas áreas de Psicologia e Neurociências. \\ Centro de Pesquisas e Análises Heráclito
}

\begin{abstract}
Henry Oh
Professor Titular da Logos University International UniLogos / Chefe do Departamento de Saúde da Idaho State University, EUA
\end{abstract}

\section{RESUMO}

A proteína Tau faz parte da família das proteínas associadas aos microtúbulos (microtubule-associated proteins - MAP) e sua principal função é a de estabilizar os microtúbulos pela agregação da tubulina. Esta proteína atua no controle da dinâmica dos microtúbulos durante a maturação e o crescimento dos neuritos, sendo considerada a maior proteína do citoesqueleto e sua hiperfosforilação tem consequência nas funções biológicas e morfológicas nos neurônios. O objetivo do presente estudo é compreender as funções da proteína Tau, bem como sua relação com as doenças neurodegenerativas. Trata-se de uma revisão de literatura nos portais científicos SciELO, PubMed e Science Direct com os seguintes termos em português: neurociência, proteína tau, doenças neurodegenerativas e em inglês: neuroscience, tau protein, neurodegenerative diseases. As doenças neurodegenerativas estão associadas aos neurofilamentos e/ou agregados de proteína Tau e o processo de hiperfosforilação da proteína, enriquece a formação destes agregados, consequentemente bloqueando o tráfego intracelular de proteínas neurotróficas e demais proteínas funcionais, e consequente perda ou diminuição do declínio no transporte axonal ou dendrítico nos neurônios.

Palavras-chaves: neurociência; proteína tau; doenças neurodegenerativas 


\title{
Tau protein and neurodegenerative diseases
}

\begin{abstract}
Tau protein is part of the microtubule-associated proteins (MAP) family and its main function is to stabilize microtubules by aggregating tubulin. This protein acts to control the dynamics of microtubules during maturation and growth of neurites, being considered the largest protein of the cytoskeleton and its hyperphosphorylation has consequences on biological and morphological functions in neurons. The aim of the present study is to understand the functions of the Tau protein, as well as its relationship with neurodegenerative diseases. This is a literature review on the scientific portals SciELO, PubMed and Science Direct with the following terms in Portuguese: neuroscience, tau protein, neurodegenerative diseases and in English: neuroscience, tau protein, neurodegenerative diseases. Neurodegenerative diseases are associated with neurofilaments and/or Tau protein aggregates and the process of protein hyperphosphorylation enriches the formation of these aggregates, consequently blocking the intracellular traffic of neurotrophic proteins and other functional proteins, and consequent loss or decrease in the decline in transport axonal or dendritic in neurons.
\end{abstract}

Keywords: neuroscience; tau protein; neurodegenerative diseases

Artículo recibido: 02 enero 2022 Aceptado para publicación: 28 enero 2022 Correspondencia: deabreu.fabiano@gmail.com Conflictos de Interés: Ninguna que declarar 
Agrela Rodrigues y Oh...

\section{INTRODUÇÃO}

\section{Proteínas Tau}

A proteína Tau é parte da família das proteínas associadas aos microtúbulos (microtubuleassociated proteins - MAP) e exerce a função de estabilizar os microtúbulos pela agregação da tubulina (Pîrşcoveanu, 2017). O gene desta proteína está localizado no braço longo do cromossomo 17 (17q21) e possui 16 éxons. No cérebro ela é caracterizada como uma proteína solúvel, com seis isoformas derivadas do splicing alternativo de RNAm e composta por 352 a 441 resíduos de aminoácidos com peso molecular aproximado de 37 a 46 kDa (Pîrşcoveanu, 2017). O splicing alternativo dos éxons 2, 3 e 10 provém da presença de seis distintas isoformas que possuem, uma, duas ou nenhuma inserção no segmento aminoterminal (Martin, 2013).

Nos mamíferos, somente as pequenas proteínas Tau são encontradas no cérebro, sendo assim, elas não apresentam nenhuma inserção 3R em suas estruturas. Quando pensamos no cérebro adulto, são expressas as isoformas $3 R$ e $4 R$. Sendo que a relação entre ambas é de 1:1, estando relacionadas com a neurodegeneração (Martin, 2013). Podem ser encontradas de maneira solúvel ou insolúvel, sendo a última encontrada nos filamentos helicoidais pareados (FHP) que se encontram de seis a oito grupos fosfato por molécula de proteína Tau (Martin, 2013).

In vitro, a fosforilação da Tau acontece através da ação de mais de dez quinases, ligadas nos sítios de treonina. Tais quinases, são divididas em dois grandes grupos de proteína: proteína quinase não dirigida por prolina e proteína quinase dirigida por prolina (prolinedirected kinase) (Martin, 2013). Nos tecidos cerebrais, o estado de fosforilação da Tau é demonstrado a partir da ação conjunta de diversas quinases e fosfatases, sendo assim, algumas operam coordenadamente para regular sua fosforilação (Martin, 2013).

\section{Funções e importância}

A proteína Tau, atua no controle da dinâmica dos microtúbulos durante a maturação e o crescimento dos neuritos. Considerada assim, como a maior proteína do citoesqueleto, a hiperfosforilação da Tau atua diretamente nas funções biológicas e morfológicas nos neurônios (Jouanne, 2017).

Ela promove a relação entre a actina e os neurofilamentos, sugerindo uma inter-relação nos microtúbulos com os demais componentes do citoesqueleto. Tais interações permitem ligações entre microtúbulos e mitocôndrias (Martin, 2013). A maturação do sistema 
nervoso central, com a progressiva ativação das fosfatases, ocorre por meio da hiperfosforilação anormal da proteína Tau, através da atividade das tauquinases, da subsensibilização das suas fosfatases ou de ambos os mecanismos (Martin, 2013).

\section{Proteína Beta-amiloide}

A proteína precursora de amiloide (PPA) possui maior concentração nas sinapses dos neurônios. Sua principal função, ainda é desconhecida, porém, sabe-se que ela atua na regulação da formação das sinapses, neuroplasticidade, e exportação de ferro (Srivastava, 2019). Também é precursora da proteólise do beta-amiloide, que é um peptídeo com 37 a 49 aminoácidos com forma fibrilar amiloide, sendo sua principal função compor as placas de amiloide que se encontram no cérebro de indivíduos com doença de Alzheimer (Srivastava, 2019).

As placas de beta-amiloide surgem do acúmulo da proteína beta-amiloide (que é solúvel) no cérebro, formando depósitos sólidos. Este acúmulo, surge nas imagens do tecido cerebral como borrões escuros, acontecendo fora das células e muito antes dos primeiros sinais da doença (Gouras, 2015).

\section{Enzima GSK-3及}

A glicogênio sintase quinase 3 (GSK-3- $\beta$ ) é uma serino-quinase, que inicialmente foi isolada como uma enzima capaz de fosforilar e inativar a enzima glicogênio sintase. Em mamíferos existem duas formas da enzima GSK-3- $\beta$, sendo codificadas em GSK3 $\alpha$ e GSK3 $\beta$. A primeira possui massa de $51 \mathrm{kDa}$, enquanto a segunda possui $47 \mathrm{kDa}$. Essa diferença é graças a extensão rica em aminoácido glicina na região $\mathrm{N}$-terminal da GSK3 $\alpha$ (Mancinelli, 2017). Apesar de haver uma alta homologia dentro de seus domínios quinase (98\%), os dois produtos compartilham somente $36 \%$ de identidade nos últimos 76 resíduos de aminoácidos C-terminais (Mancinelli, 2017).

Antigamente, acreditava-se que a GSK3 fosse uma proteína quinase com função confinada ao metabolismo do glicogênio, porém atualmente, sabe-se que exerce importância na regulação de diversas funções celulares, como por exemplo a sinalização pela insulina, fatores de crescimento e nutrientes e a especificação dos destinos das células durante o desenvolvimento embrionário, além de controle da divisão celular, apoptose e função dos microtúbulos (Yang, 2017).

Já foi demonstrado também que as células desenvolvem mecanismos para parar a atividade da GSK3 em resposta a diversos sinais que estão conectados de uma forma 
intrigante pela especificidade única desta enzima pelo substrato (Yang, 2017). Sendo assim, o objetivo do presente estudo é compreender as funções da proteína Tau, bem como sua relação com as doenças neurodegenerativas.

\section{DESENVOLVIMENTO}

Trata-se de uma revisão de literatura nos portais científicos SciELO, PubMed e Science Direct, com os seguintes termos em português: neurociência, proteína Tau, doenças neurodegenerativas e em inglês: neuroscience, Tau protein, neurodegenerative diseases.

\section{RESULTADOS}

Doença neurodegenerativa é o termo denominado para as doenças que atacam o sistema nervoso. A principal característica e mais comum entre as patologias deste grupo é a morte dos neurônios. Como exemplos mais comuns tem-se: doença de Alzheimer (DA), Parkinson, esclerose múltipla, esclerose lateral amiotrófica (ELA), Huntington (Hou, 2019)

Figura 1 - Diferenças esquemáticas entre um neurônio saudável (A) e um neurônio de um paciente com DA (B)

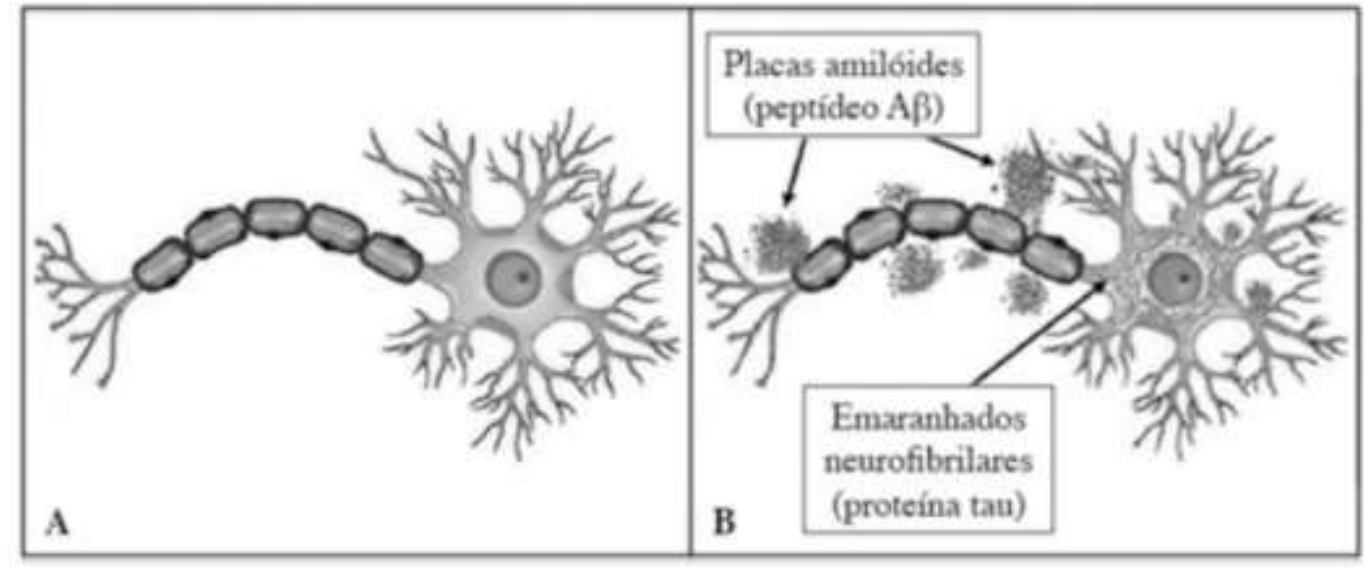

Fonte: Adaptado de Rey, N.A. et al. 2016

Atualmente vem surgindo um crescimento dos estudos em relação as doenças neurodegenerativas, seguindo duas linhas de pesquisa principais: estudo da bioquímica das lesões patológicas que definem e identificam a doença por seus componentes moleculares e a segunda estuda as formas familiares da doença, identificando genes defeituosos que causam diferentes variantes patológicas (Hou, 2019).

Tais doenças com a associação de neurofilamentos e/ou agregados de proteína Tau são denominados em quatro grupos: doença poliglutamínica, doenças com ubiquitina, 
tauopatias e alfa-sinucleinopatias (Hou, 2019). Sendo assim, o acúmulo intracelular da proteína Tau hiperfosforilada em neurônios ou células gliais, é um importante marcador biológico das tauopatias (Rusek, 2019).

A hiperfosforilação induz a diminuição da capacidade de a proteína Tau estabilizar os microtúbulos, comprometendo a dinâmica microtubular e consequentemente o transporte intraneuronal, apresentando assim efeitos deletérios nos processos celulares (Rusek, 2019). Tais erros na atuação da proteína podem alterar o transporte axonal, que são fatores primordiais para manter a homeostase neuronal. O processo para regular a dinâmica dos microtúbulos (estabilização e desestabilização) fator importante para que ocorra a preservação da morfologia e das funções celulares (Rusek, 2019).

A adição da expressão da Tau, leva a alterações na morfologia celular, diminuindo seu crescimento, provocando assim alterações importantes na distribuição de organelas que são conduzidas através das proteínas motoras dependentes de microtúbulos (Bakota, 2016). A hiperfosforilação da Tau no citosol atua nos estágios iniciais do processo de degeneração neurofibrilar, induzindo mudanças em sua agregação (Bakota, 2016). A proteína Tau, em indivíduos com doença de Alzheimer, não atua corretamente, ela se separa dos microtúbulos e cria formas desorganizadas que obstruem os mesmos, porém não se sabe ainda o que provoca tais processos (Bakota, 2016).

O substrato neuropatológico da doença de Alzheimer é a presença de placas amiloides e emaranhados neurofibrilares, tais como perdas sinápticas, degeneração neuronal (apoptose), infiltrado inflamatório e angiopatia amiloide. As placas senis são depósitos extracelulares esféricos de agregados insolúveis da proteína beta-amiloide, estando localizadas no sistema límbico (hipocampo, córtex entorrinal, amígdala e em algumas áreas corticais e subcorticais) (Soria, 2019).

Os agregados neurofibrilares são grupos intracitoplasmáticos de filamentos helicoidais pareados, compostos pela proteína Tau hiperfosforilada. As placas senis são provenientes de peptídeos beta-amiloides (A-beta) produzidos por meio da clivagem da proteína precursora amiloide (APP) pela enzima alfa-secretase seguida da gama-secretase (via amiloidogênica) formando fragmentos peptídicos com alto potencial tóxico, pois podem se agregar, gerando a formação de placas amiloides insolúveis.

Em indivíduos com doença de Alzheimer, a A-beta-40 (peptídeo beta-amiloide de 40 aminoácidos de extensão) é desenvolvida em pequenas quantidades, enquanto há uma 
superprodução de A-beta-42, que é mais tóxica devido seu potencial de agregação ser superior (Srivastava, 2019).

Uma das funções da GSK3 é a regulação positiva no processo inflamatório, sendo importante devido a diversas doenças terem como característica comum a inflamação crônica. Como por exemplo: doenças psiquiátricas (com foco no transtorno do humor bipolar), doenças neurodegenerativas (doença de Alzheimer), diabetes e câncer (Srivastava, 2019).

Figura 2 - Mecanismos de ação da GSK3

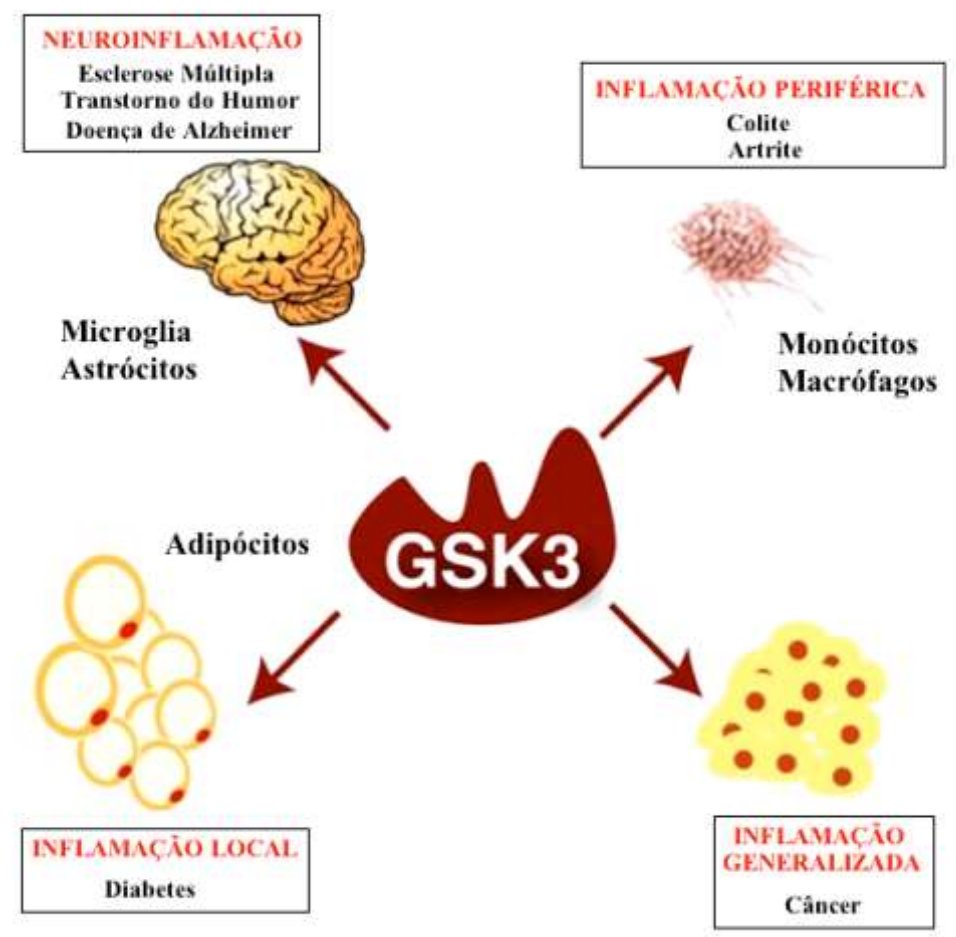

Fonte: Adaptado de Martins, LM. 2013

A inflamação na parte central do sistema nervoso é quantificada por meio da microglia e pelos astrócitos, assim como, as células que se infiltram, contribuindo para uma grande variedade de patologias, tais como: a esclerose múltipla, transtornos do humor e doenças neurodegenerativas, incluindo doença de Alzheimer. Essa inflamação periférica é mediada, em parte, por monócitos e macrófagos, e a GSK3 favorece condições inflamatórias como colite e artrite. Inflamação local, como a produção de citosina através dos adipócitos e pode contribuir ao desenvolvimento de diabetes podendo ser influenciada pela GSK3 ativa. A inflamação também pode contribuir para numerosos tipos de câncer (Martins, 2013). 


\section{CONCLUSÃO}

As proteínas Tau, produto de splicing alternativo (processo pelo qual éxons de um transcrito primário são clivados em locais diferentes na molécula de RNA recémsintetizada) de um único gene, são abundantes nos neurônios do sistema nervoso central e responsáveis pela estabilidade dos microtúbulos (estruturas protéicas que fazem parte do citoesqueleto e são formados pela polimerização das proteínas tubulina e almetralopina). Quando possuem defeito, não estabilizam bem os microtúbulos levando ao aparecimento de estados de demência.

A presença de $A \beta$ (Beta-amiloide) leva os neurônios a hiperfosforilar a proteína Tau de ligação do microtúbulo e este nível aumentado redistribui a Tau no interior do axônio para os dendritos e corpo celular gerando aglomerados; este processo vai resultar em disfunção ou morte neuronal levando a doenças neurodegenerativas.

As placas, depósitos anormais de fragmentos de proteína, se agrupam entre os neurônios que contém um emaranhado neurofibrilar formado por filamentos torcidos de outra proteína. Essas placas são formadas quando pedaços de proteínas chamados betaamiloide se agrupam, e sendo quimicamente "pegajosos" se juntando e formando placas. Os pequenos agrupamentos bloqueiam a sinalização entre os neurônios nas sinapses e podem ativar células do sistema imunológico causando inflamações e devorando células deficientes.

A GSK-3 é uma serina-treonina quinase dirigida por prolina que foi inicialmente identificada como um agente fosforilador e inativador do glicogênio sintase. Duas isoformas, alfa e beta, mostram um alto grau de homologia de aminoácidos. GSK-3-Beta está envolvida no metabolismo energético, no desenvolvimento de células neuronais e na formação de padrões corporais. A GSK-3 tem sido objeto de pesquisas, uma vez que está relacionado a uma série de doenças, incluindo diabetes tipo 2, doença de Alzheimer, inflamação, câncer e transtorno bipolar.

Sabendo-se destes efeitos, alguns estudos encontraram ligação do mineral lítio, encontrado em grãos, carne bovina, ovos e verduras, como efeito neuroprotetor inibindo a enzima GSK-3-Beta que tem um papel importante na degeneração de neurônios. Sugerindo que a inibição da atividade da GSK-3-Beta com tratamento crônico com lítio em neurônios hipocampais obtendo efeito contrário em neurônios corticais e sem alterações na proteína Tau. 


\section{REFERÊNCIAS}

BAKOTA, L., Brandt, R. Tau Biology and Tau-Directed Therapies for Alzheimer's Disease. Drugs. n. 76, v. 3 págs. 301-13, 2016 doi: 10.1007/s40265-015-0529-0.

BIGMAN, L.S., Levy, Y. Proteins: molecules defined by their trade-offs. Curr Opin

Struct Biol. n. 60, págs. 50-56, 2020 doi: 10.1016/j.sbi.2019.11.005.

Gouras GK, Olsson TT, Hansson O. $\beta$-Amyloid peptides and amyloid plaques in Alzheimer's disease. Neurotherapeutics. Jan n. 12, v. 1 págs.13-11, 2015 doi: 10.1007/s13311-014-0313-y.

Hou Y, Dan X, Babbar M, Wei Y, Hasselbalch SG, Croteau DL, Bohr VA. Ageing as a risk factor for neurodegenerative disease. Nat Rev Neurol. n. 15, v.10, págs. 565581, 2019 doi: 10.1038/s41582-019-0244-7.

JOUANNE, M., Rault, S., Voisin-Chiret, A.S. Tau protein aggregation in Alzheimer's disease: An attractive target for the development of novel therapeutic agents. Eur J Med Chem. n. 20, v. 139, págs. 153-167, 2017 doi: 10.1016/j.ejmech.2017.07.070.

KO, P.J., Dixon, S.J. Protein palmitoylation and cancer. EMBO Rep. n. 19, v. 10, e46666, 2018 doi: 10.15252/embr.201846666.

MAGALHÃES, L. Proteínas. Toda Matéria, 2020

Mancinelli R, Carpino G, Petrungaro S, Mammola CL, Tomaipitinca L, Filippini A, Facchiano A, Ziparo E, Giampietri C. Multifaceted Roles of GSK-3 in Cancer and Autophagy-Related Diseases. Oxid Med Cell Longev. n. 20, v. 17 e4629495, 2017doi: 10.1155/2017/4629495.

MARTIN, L., Latypova, X., Wilson, C.M., Magnaudeix, A., Perrin, M.L., Yardin, C., Terro, F. Tau protein kinases: involvement in Alzheimer's disease. Ageing Res Rev. n. 12, v. 1, págs. 289-309, 2013 doi: 10.1016/j.arr.2012.06.003

Martins, L.M Santos, J.R.S. Inibição do glicogênio sintase cinase 3 como Nova abordagem no controle da dor aguda e Crônica: análise dos mecanismos de ação. [Tese] Universidade Federal de Santa Catarina, 2013

PANCSA, R., Schad, E., Tantos, A., Tompa, P. Emergent functions of proteins in nonstoichiometric supramolecular assemblies. Biochim Biophys Acta Proteins Proteom. n. 1867, v.10 págs. 970-979, 2019 doi: 10.1016/j.bbapap.2019.02.007. Paz, D.P. Bioquímica de proteínas: Proteína Tau. Passei direto, 2020 
PÎRŞCOVEANU, D.F.V, Pirici, I., Tudorică, V., Bălşeanu, T.A., Albu, V.C., Bondari, S., Bumbea, A.M., Pîrşcoveanu, M. Tau protein in neurodegenerative diseases - a review. Rom J Morphol Embryol. n. 58, v. 4, págs.1141-1150, 2017

Rey, N.A. Rachel, A. Cukierman, S.D. Falco, A.D. Doença de alzheimer: hipóteses etiológicas e perspectivas de tratamento. Revista Química Nova. n. 39 v. 1, 2016 doi: https://doi.org/10.5935/0100-4042.20150152

RUSEK, M., Pluta, R., Ułamek-Kozioł, M., Czuczwar, S.J. Ketogenic Diet in Alzheimer's Disease. Int J Mol Sci. Aug n. 9, v. 20 e3892, 2019 doi: 10.3390/ijms20163892.

Soria Lopez JA, González HM, Léger GC. Alzheimer's disease. Handb Clin Neurol. n. 167, págs. 231-255, 2019 doi: 10.1016/B978-0-12-804766-8.00013-3.

Srivastava AK, Pittman JM, Zerweck J, Venkata BS, Moore PC, Sachleben JR, Meredith SC. $\beta$-Amyloid aggregation and heterogeneous nucleation. Protein Sci. n. 28, v. 9, págs.1567-1581, 2019 doi: 10.1002/pro.3674.

Yang K, Chen Z, Gao J, Shi W, Li L, Jiang S, Hu H, Liu Z, Xu D, Wu L. The Key Roles of GSK-3 $\beta$ in Regulating Mitochondrial Activity. Cell Physiol Biochem. n. 44, v.4, págs.1445-1459, 2017 doi: 10.1159/000485580. 